\title{
IN-SITU SYNTHESIS OF MULTICOMPONENT ALLOYS FROM Ni BASED ELEMENTAL POWDERS BY DIRECT LASER DEPOSITION
}

\author{
Dmitriy MASAYLO, Sergei IGOSHIN, Anatoliy POPOVICH \\ Peter the Great St. Petersburg Polytechnic University, St. Petersburg, Russia, \\ dmasaylo@gmail.com, sergei.igosshin@gmail.com,popovicha@mail.ru
}

https://doi.org/10.37904/metal.2021.4220

\begin{abstract}
The paper investigates an approach to the synthesis of classical heat-resistant alloys by laser cladding (LC) or direct laser deposition (DLD). This approach corresponds to the concept of developing the production of small parties of metal products with the economically feasible use of additive technologies. The results of already obtained materials from pure elemental powders and the prospects for the development of such formation of alloys from the liquid phase, as well as metal-matrix composites by 3D printing, are discussed. The paper presents the result of a specimen formation from a mechanical mixture of $\mathrm{Ni} / \mathrm{Cr} / \mathrm{Fe}$ powder, in the mass ratio of the main components, close in composition to the alloy Inconel 600. The produced multilayer specimen was studied by optical and electron microscopy. Measurement of fluctuations in the chemical composition in the specimen to determine the degree of diffusion of elements in the alloy was carried out. The formation of chromium oxide clusters along the boundaries of the tracks, which, presumably, diffuse in the direction of heat removal during crystallization from the melt, was found. The structure of the specimen is represented by large, elongated grains up to $1-2 \mathrm{~mm}$ in size, significantly exceeding the height of one pass. The direction of grain growth corresponds to the growth direction of the specimen in the direction of the $Z$ axis.
\end{abstract}

Keywords: Direct laser deposition, laser cladding, powder metallurgy, alloy synthesis, nickel and iron alloys

\section{INTRODUCTION}

The introduction of metal additive technologies in the real economic sector may now be a priority for maintaining the growth rate of this area of industrial production. The advantage of the introduction of additive technologies is the ability to reduce the number of operations when obtaining the final product from the raw material. Many people know about the technology of metal printing, using the method of powder bed fusions, which is called selective laser melting (SLM). The units that use this technology are supplied as a complete self-sufficient system that allows you to make parts from a variety of materials according to the modes already worked out by the manufacturer. The cost of such machines is quite high, and the maximum dimensions of the working chamber usually do not exceed $500 \mathrm{~mm}$ for each of the coordinates. There are alternative solutions these are installations that work on the principle of direct feeding of the material into the melting zone, for example - laser cladding (LC) or direct laser deposition (DLD). This is more affordable equipment, usually based on a 6-axis industrial robot manipulator, which allows you to produce large parts with a size of $1500 \mathrm{~mm}$ or more.

The principle of operation of direct laser deposition consists in feeding the building material (powder or wire) into the melting zone with the formation of a melt bath by a laser beam and subsequent crystallization of the metal in the form of hemispherical tracks. As a starting material, powders from traditional alloys, from mechanoalloyed powders, as well as from mixtures of elemental powders can be used. The construction of parts made of pre-alloyed alloys has already been fully studied in scientific works [1-5]. The influences of the surfacing 
parameters, the technological parameters of the powders themselves, as well as the physics of the main processes were studied. The method of obtaining alloys from mechano-alloyed powders is designed to reduce the cost of processing secondary raw materials, as well as to obtain materials from pseudo-alloys [6-8]. Alloys from powder element mixtures do not require special technological operations before DLD, so they may be the cheapest raw material to produce alloys. The main issue is the degree of uniformity of the final alloy and the stability of the chemical composition relative to the initial mixture. Known work on DLD from elemental powders of the Fe-Cr-Ni system [9]. The authors synthesized an alloy with different contents of the components of the elemental mixture. Thin walls were made as samples. The point-by-point EDS results have shown that optimizing the particle size of the finished blend is necessary to maintain the original blend and reduce the separation of the premixed powder. The produced heterogeneous and multifunctional Fe-Cr-Ni alloy has both corrosion resistance and sufficient toughness and ductility. In [10], critical technical problems of the synthesis of alloys from elemental powders for future development are discussed. It is noted that today there are many unresolved issues, such as overcoming the entropy of mixing, flow behavior for various metal powders, and how the interaction of laser and material affects the final composition of the finished part. In addition, it is necessary to deduce a predictable relationship between the initial atomic or mass composition and the final composition of the finished alloy. The field of research on the production of high-entropy alloys from a mixture of powders is developing, since it is almost impossible to obtain traditional alloys from this type of material. Various high-entropy alloys of the FeCoNiCrCu [11], 6FeNiCoSiCrAlTi [12], TiVCrAISi [13] and others systems were synthesized using laser technologies.

The ability to synthesize the alloy in the growing process allows you to obtain alloys with different functional properties depending on the proportion of the components and allows you not to purchase many different powder alloys. Therefore, it can be assumed that the production of alloys from elementary powders may not only be of scientific interest, but also be a cost-effective method of production.

The purpose of this work was to evaluate the quality of the alloy obtained by the method of synthesis of elementary powders by DLD and to investigate the problems that arise in the formation of the material structure and the formation of the alloy in the process of constructing multilayer samples.

\section{METHODOLOGY AND EXPERIMENT}

$\mathrm{Ni}, \mathrm{Fe}$, and $\mathrm{Cr}$ elemental powders were used in the delivery state. The characteristics of these powders are presented in Table 1. Then, the elemental powders were mechanically mixed by gravity for 4 hours in a mass ratio of $73 \% \mathrm{Ni}, 17 \% \mathrm{Cr}, 10 \% \mathrm{Fe}$ until a homogeneous mixture was formed. This mixture was loaded into the powder feeder of the laser surfacing unit. The surfacing was carried out on a sheet of structural low-alloy steel of the St.3 grade with a thickness of $5 \mathrm{~mm}$. The chemical composition of the substrate (in wt\%) is iron 97 , carbon 0.22; nickel, copper, chromium - each no more than 0.3 ; manganese 0.65 ; silicon 0.17 .

Synthesis and production of samples using laser cladding technology was carried out at the plant developed in SPBPU. The main components of the unit continuous ytterbium fiber laser iPG LS-3, powder feeder PF 2/2, optical system (cladding head) KUKA MWO-1 and Fanuc M20i robot. Method of melting zone protection: local protection by argon supply, without filling the working chamber with argon.

The experiment consisted in growing c samples from elemental powders by the DLD method to obtain a homogeneous alloy and simultaneously form the sample. The modes for which the process was carried out are shown in Table 2. First, a series of single tracks was made with a change in the amount of energy supplied due to a change in the laser power $(900,1200,1500$ and $2000 \mathrm{~W})$. Then thin-walled and thick-walled samples were grown at a laser power of 1200 and $1500 \mathrm{~W}$. 
Table 1 Elemental powders for synthesis Ni-Cr-Fe alloy

\begin{tabular}{|c|c|c|c|}
\hline Powder & Particle size $(\mu \mathrm{m})$ & Particle shape & Chemical composition (wt\%) \\
\hline $\mathrm{Ni}$ & $5-55$ & & $\begin{array}{l}\mathrm{Ni}-99.25 \\
\text { The rest including } \mathrm{O}-0.75\end{array}$ \\
\hline $\mathrm{Cr}$ & $5-55$ & & $\begin{array}{c}\mathrm{Cr}-98.76 \\
\mathrm{Si}-0.22 \\
\text { The rest including } \mathrm{O}-1\end{array}$ \\
\hline $\mathrm{Fe}$ & $20-125$ & & $\begin{array}{c}\mathrm{Fe}-98.19 \\
\mathrm{Mn}-0.45 \\
\text { The rest including } \mathrm{O}-1.36\end{array}$ \\
\hline
\end{tabular}

All samples were cut and metallographic sections were made from them. Chemical etching of metallographic sections was carried out in a solution of $10 \mathrm{ml} \mathrm{HNO}_{3}$ and $30 \mathrm{ml} \mathrm{HCl}$. Photos of the microstructure were obtained using a Leica optical microscope. Chemical analysis was carried out on SEM Tescan Mira 3 electron microscope with EDS attachment. X-ray phase analysis was carried out on Bruker D8 Advance diffractometer in the range of 200 to 1000 angles with 0.02 step and $2 \mathrm{~s}$ exposure time at each step. Quantitative phase analysis was performed using TOPAS5 software.

Table 2 DLD parameters for growing samples from elementary powders

\begin{tabular}{|l|c|}
\hline DLD parameter & Parameter value \\
\hline Speed of movement & $10 \mathrm{~mm} / \mathrm{s}$ \\
\hline Powder feed & $15 \mathrm{~g} / \mathrm{min}$ \\
\hline Protective argon & $12 \mathrm{l} / \mathrm{min}$ \\
\hline Transport argon & $61 / \mathrm{min}$ \\
\hline Laser power & $900-2000 \mathrm{~W}$ \\
\hline Lifting height & $0.6 \mathrm{~mm}$ \\
\hline Offset & $50 \%$ \\
\hline Laser spot size & $3 \mathrm{~mm}$ \\
\hline
\end{tabular}

\section{RESULT AND DISCUSSION}

The structure of single tracks on a steel substrate is investigated. The etched samples in Figure 1 show a clear boundary between the substrate and the synthesized alloy, as well as the heat affected zone (HAZ). According to the state of the structure for laser powers of 900-1500 W (Figures 1 a-c), one can note the presence of vortex flows and turbulent flow of liquid in a bath of dissimilar liquid melt prior to crystallization. At a laser power of $2000 \mathrm{~W}$, there are no vortex flows on the structure, and there is directional crystallization characteristic of tracks of homogeneous alloys. 

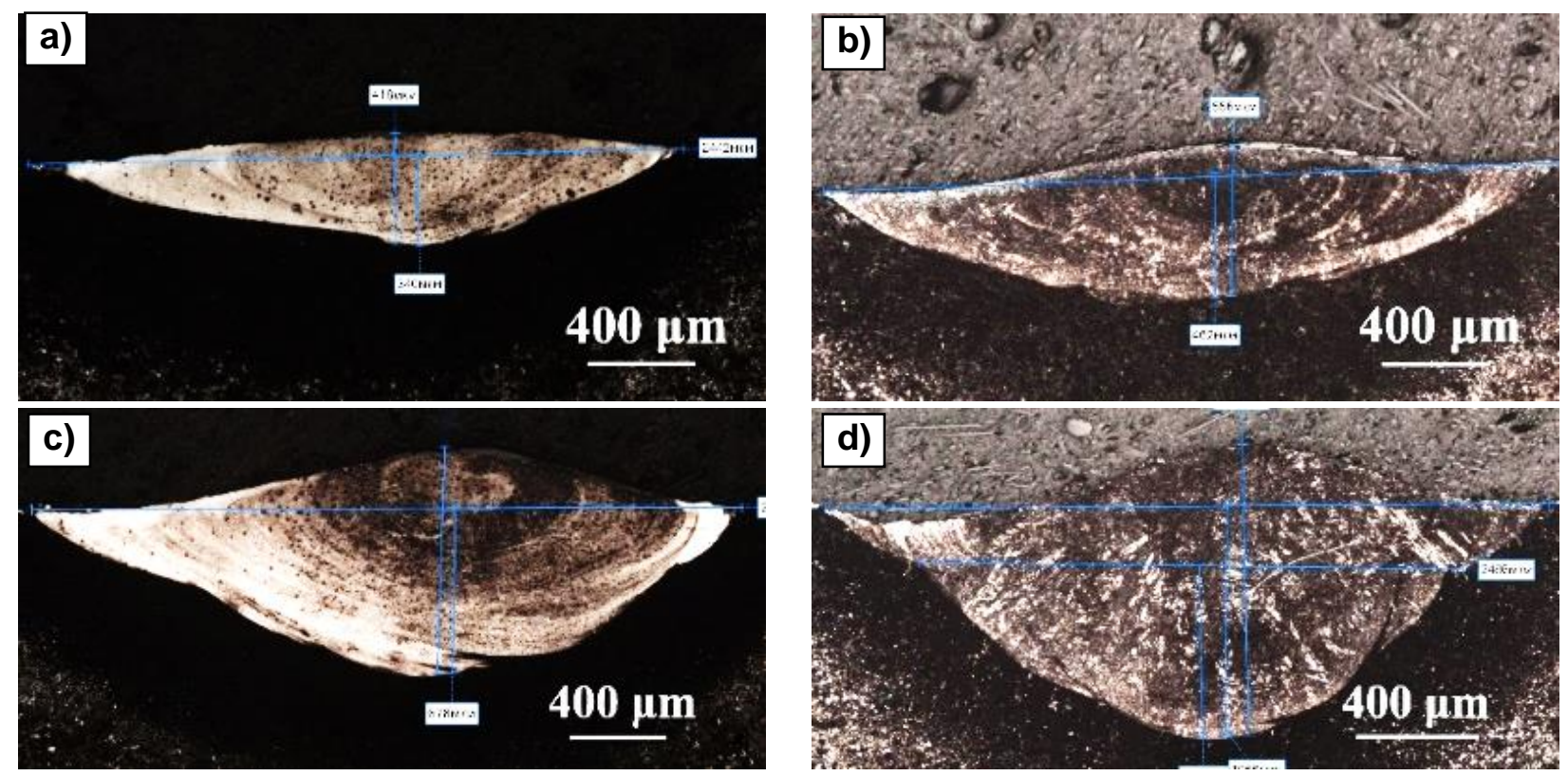

Figure 1 Single tracks from an iron-based Ni/Cr/Fe mixture: a) 900 W, b) $1200 \mathrm{~W}$, c) $1500 \mathrm{~W}$, d) $2000 \mathrm{~W}$

The EDS method was used to determine the chemical composition of the tracks by area, which showed the presence of iron diffusion from the substrate (Table 3). Since the DLD process is characterized by the formation of a melt bath, it can be assumed that the volume of the molten substrate material significantly exceeds the volume of the introduced metal. For this reason, when surfacing a single track of elemental powders, the chemical composition is dominated by the elements of the substrate.

Table 3 The content of chemical elements (wt\%) in the track depending on the laser power

\begin{tabular}{|c|c|c|c|}
\hline Laser power $(\mathrm{W})$ & $\mathbf{N i}$ & $\mathbf{C r}$ & $\mathbf{F e}$ \\
\hline 900 & 3.5 & 4.9 & 91.6 \\
\hline 1200 & 2.8 & 2.5 & 94.7 \\
\hline 1500 & 6.1 & 4.6 & 89.3 \\
\hline 2000 & 2.7 & 2.7 & 94.6 \\
\hline
\end{tabular}

Also, the dependence of the size of the track bath (formed melt bath) depending on the laser power was revealed. This dependence, expressed in the final geometric size of the track, is shown in Figure 2.
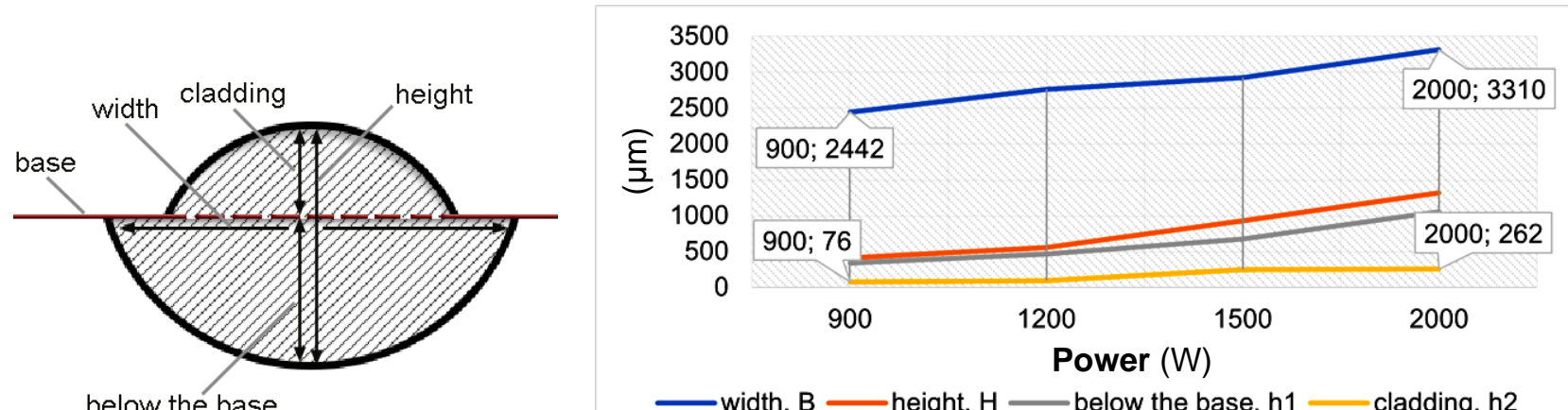

Figure 2 Parameters of the track geometry depending on the laser power 
An SEM image with combined EDS analysis of a thin-walled sample grown at a power of $1500 \mathrm{~W}$ is shown in Figure 3.

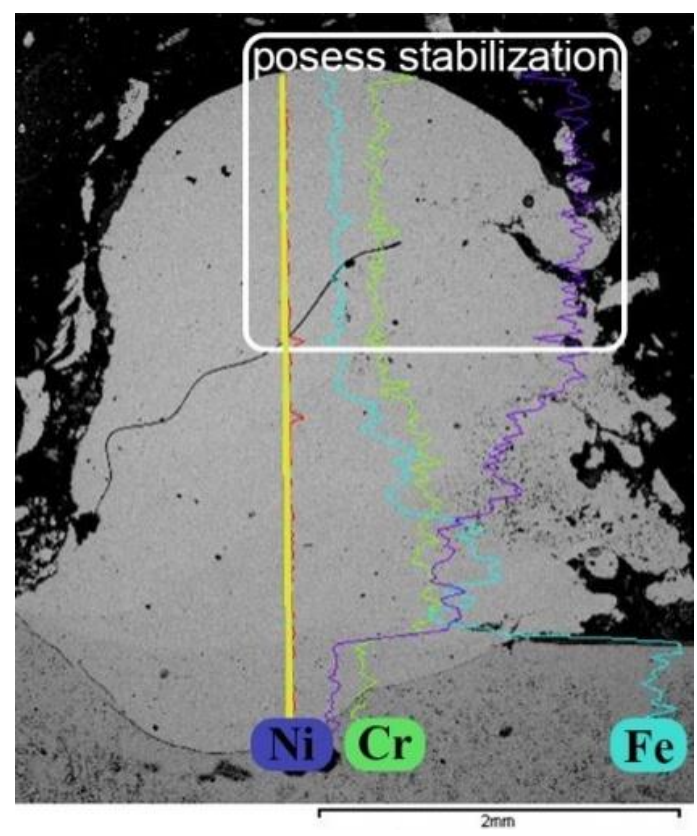

Figure 3 Cladding of a thin wall from an elemental $\mathrm{Ni} / \mathrm{Cr} / \mathrm{Fe}$ mixture at a power of $1500 \mathrm{~W}$

The thin wall has an irregular shape and many protrusions due to the too small size of the powder, which led to the penetration of the powder particles along the boundaries of the walls and the formation of satellites. About the chemical composition of the thin wall, there is a gradient of the chemical composition in height, but the stabilization of the chemical composition occurs at a wall height of $2 \mathrm{~mm}$, which corresponds to approximately 3 layers. This result suggests that when synthesizing low samples or coatings, the chemical composition of the alloy will be significantly affected by the substrate material, which must be borne in mind when selecting a powder mixture.

a)

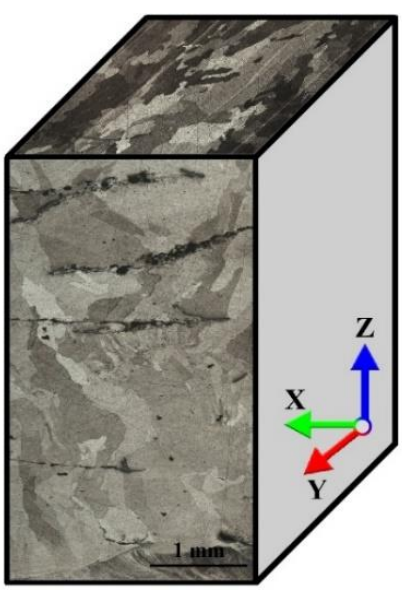

b)

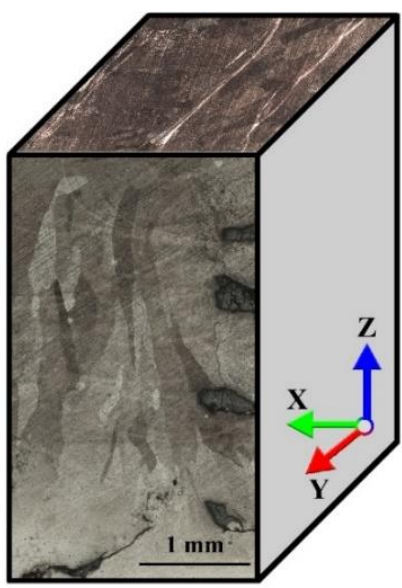

Figure 4 Structure of synthesized thick-walled samples of the $\mathrm{Ni} / \mathrm{Cr} / \mathrm{Fe}$ system. a) the laser power 1200

$\mathrm{W}, \mathrm{b})$ the laser power $1500 \mathrm{~W}$. New layers were added in the $\mathrm{Z}$ direction

Further, the structure and chemical composition of the synthesized thick-walled samples were studied. Depending on the laser power, the sample structure changed significantly. At a laser power of $1200 \mathrm{~W}$, the orientation of the grains was found mainly in the direction of the growth of the thick wall. At a laser power of 
$1500 \mathrm{~W}$, the grain orientation becomes even more pronounced with a cell size in one direction of about $2 \mathrm{~mm}$. This structure indicates the heating of the sample during thermal cycling above the recrystallization temperature and directed cooling.

To control the change in the chemical composition by volume, thin-walled samples were examined on EDS in three zones (Figure 5). The measurement results are shown in Table 4.

a)

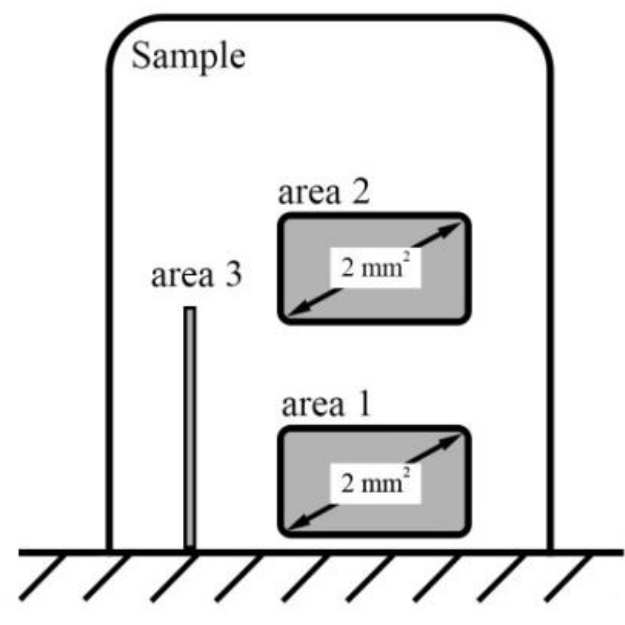

b)

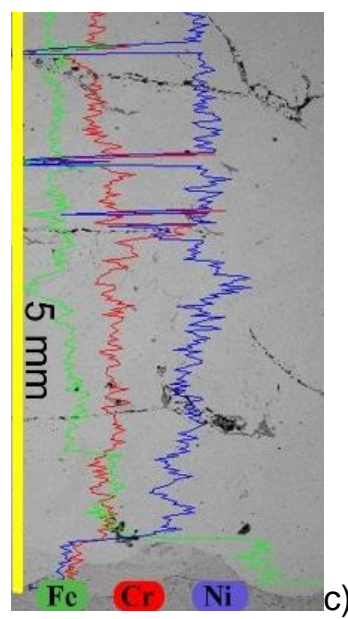

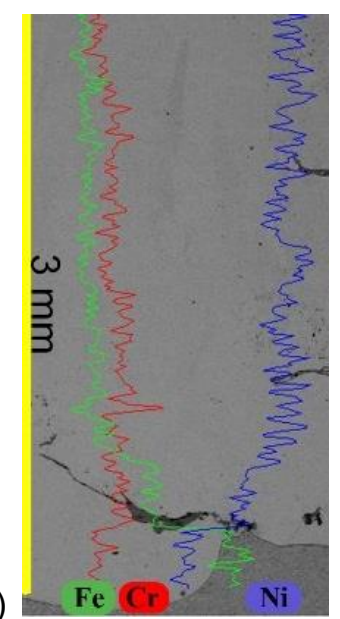

Figure 5 EDS analysis in thick-walled samples. a) diagram of the areas for measuring the chemical composition, measuring the change in the chemical composition in zone 3 for laser power: b) $1200 \mathrm{~W}$ and c) $1500 \mathrm{~W}$

Table 4 Chemical composition (wt\%) of samples from a Ni / Cr / Fe mixture for two laser powers in zones 1 and 2 .

\begin{tabular}{|c|c|c|c|c|c|c|c|c|}
\hline & \multicolumn{4}{|c|}{$1200 \mathrm{~W}$} & \multicolumn{4}{|c|}{$1500 \mathrm{~W}$} \\
\hline element & 0 & $\mathrm{Cr}$ & $\mathrm{Fe}$ & $\mathbf{N i}$ & 0 & $\mathrm{Cr}$ & $\mathrm{Fe}$ & $\mathbf{N i}$ \\
\hline value for area 1 & $<0.5$ & 18.3 & 12.0 & 69.7 & 1.6 & 13.4 & 13.1 & 72.0 \\
\hline value for area 2 & 2.8 & 16.9 & 8.9 & 71.4 & $<0.5$ & 11.0 & 12.4 & 76.6 \\
\hline
\end{tabular}

\section{Optical image of inclusions}

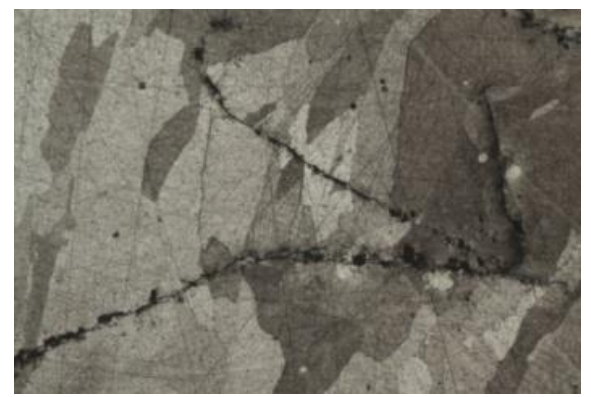

SEM

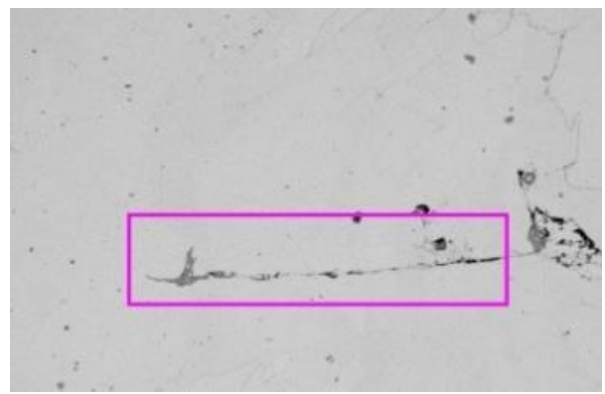

\section{EDS}

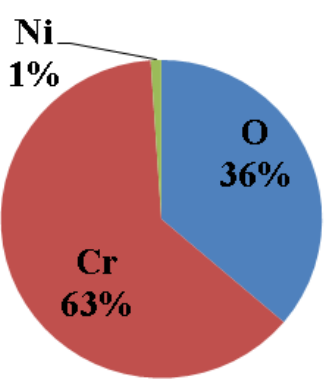

Figure 6 Study of defects in the Ni-Cr-Fe alloy

No unalloyed powder particles were found, but as can be seen from the structural images in Figure 4, there are a significant number of defects in the samples - inter-track oxide inclusions (Figure 6). With an increase in the laser power, the chromium content in the alloy decreased by $5 \%$ due to an increase in the number of oxide phases. A comprehensive study of the chemical composition by the EDS method of a thin-walled sample showed the instability of the distribution of elements within the volume of the material. The reason for this 
instability is based on the formation of oxide inclusions, which were identified as chromium oxide. With an increase in the laser power from $1200 \mathrm{~W}$ to $1500 \mathrm{~W}$, the distribution of oxide inclusions changed. Thin inclusions distributed mainly along the track boundaries agglomerated between tracks into ellipsoidal inclusions with a diameter of $0.3-0.5 \mathrm{~mm}$.

\section{CONCLUSION}

The following results were obtained in the work:

- Synthesis of the alloy by the DLD method from elemental powders showed a high diffusion of the elements of the substrate material in the first 1-2 layers of surfacing, which can significantly change the chemical composition of the alloy;

- At a laser power of $1200 \mathrm{~W}$, all the powder melted down and participated in the formation of an alloy;

- An increase in the laser power from $1200 \mathrm{~W}$ to $1500 \mathrm{~W}$ during DLD from elemental powders, the length of the grains increases to elongated crystals $12 \mathrm{~mm}$ long along the heat removal axis.

- The elimination of the conditions for the formation of oxide inclusions, namely the protective oxygen-free chamber, as well as the minimum oxygen content in the powders, should improve the quality of synthesis from elemental powders;

- It is planned to determine the functional properties of the material heat resistance and heat resistance, it is necessary to conduct additional studies and compare with the properties of pre-alloyed alloys of similar composition

\section{ACKNOWLEDGEMENTS}

We acknowledge the support from Russian Science Foundation grant (project №. 19-79-30002).

\section{REFERENCES}

[1] MAHAMOOD, R.M. Laser metal deposition process of metals, alloys, and composite materials. [online]. Springer International Publishing, Cham, 2018. Available from: https://doi.org/10.1007/978-3-319-64985-6.

[2] QIU, C., RAVI, G.A., DANCE, C., RANSON, A., DILWORTH, S., ATTALLAH, M.M. Fabrication of large Ti-6AI-4V structures by direct laser deposition. J. Alloys Compd. [online]. 2015, vol. 629, pp. 351-361. Available from: https://doi.org/10.1016/j.jallcom.2014.12.234.

[3] ZHANG, K., LIU, W., SHANG, X.Research on the processing experiments of laser metal deposition shaping, Opt. Laser Technol. [online]. 2007, vol. 39, pp. 549-557. Available from: https://doi.org/10.1016/..optlastec.2005.10.009.

[4] SHAMSAEI, N., YADOLLAHI, A., BIAN, L., THOMPSON, S.M. An overview of Direct Laser Deposition for additive manufacturing. Part II: Mechanical behavior, process parameter optimization and control. Addit. Manuf. [online]. 2015, vol. 8, pp. 12-35. Available from: https://doi.org/10.1016/j.addma.2015.07.002.

[5] THOMPSON, S.M., BIAN, L., SHAMSAEI, N., YADOLLAHI, A. An overview of Direct Laser Deposition for additive manufacturing; Part I: Transport phenomena, modeling and diagnostics. Addit. Manuf. [online]. 2015, vol. 8, pp. 36-62. Available from: https://doi.org/10.1016/j.addma.2015.07.001.

[6] SAVINOV, R., WANG, Y., SHI, J. Microstructure and properties of $\mathrm{CeO}_{2}$-doped CoCrFeMnNi high entropy alloy fabricated by laser metal deposition. J. Manuf. Process. [online]. 2020, vol. 56, pp. 1245-1251. Available from: https://doi.org/10.1016/i.jmapro.2020.04.018.

[7] POLOZOV, I., SUFIIAROV, V., KANTYUKOV, A., RAZUMOV, N., GONCHAROV, I., MAKHMUTOV, T., SILIN, A., KIM, A., STARIKOV, K., SHAMSHURIN, A., POPOVICH, A. Microstructure, densification, and mechanical properties of titanium intermetallic alloy manufactured by laser powder bed fusion additive manufacturing with high-temperature preheating using gas atomized and mechanically alloyed plasma spheroidized powders. Addit. Manuf. [online]. 2020, vol. 34, p. 101374. Available from: https://doi.org/10.1016/j.addma.2020.101374. 
[8] POLOZOV, I., POPOVICH, V., RAZUMOV, N., MAKHMUTOV, T., POPOVICH, A. Gamma-titanium intermetallic alloy produced by selective laser melting using mechanically alloyed and plasma spheroidized powders. [online]. In: 2020: pp. 375-383. Available from: https://doi.org/10.1007/978-3-030-36296-6 35.

[9] LI, W., YAN, L., CHEN, X., ZHANG, J., ZHANG, X., LIOU, F. Directed energy depositing a new Fe-Cr-Ni alloy with gradually changing composition with elemental powder mixes and particle size' effect in fabrication process, J. Mater. Process. Technol. [online]. 2018, 255, pp. 96-104. Available from: https://doi.org/10.1016/j.jmatprotec.2017.12.010.

[10] CHEN, Y., ZHANG, X., PARVEZ, M.M., LIOU, F. A review on metallic alloys fabrication using elemental powder blends by laser powder directed energy deposition process. Materials (Basel). [online]. 2020, vol. 13, p. 3562. Available from: https://doi.org/10.3390/ma13163562.

[11] ZHANG, H., PAN, Y., HE, Y.Z. Synthesis and characterization of FeCoNiCrCu high-entropy alloy coating by laser cladding. Mater. Des. [online]. 2011, vol. 32, pp. 1910-1915. Available from: https://doi.org/10.1016/j.matdes.2010.12.001.

[12] ZHANG, H., PAN, Y., HE, Y., JIAO, H. Microstructure and properties of 6FeNiCoSiCrAITi high-entropy alloy coating prepared by laser cladding. Appl. Surf. Sci. 2011, vol. 257, pp. 2259-2263.

[13] HUANG, C., ZHANG, Y., SHEN, J., VILAR, R. Thermal stability and oxidation resistance of laser clad TiVCrAISi high entropy alloy coatings on Ti-6AI-4V alloy. Surf. Coatings Technol. 2011, vol. 206, pp. 1389-1395. 